\title{
A Low Melting Point Solder For 22 Carat Yellow Gold
}

\author{
David M Jacobson and Satti P S Sangha \\ Hirst Division, \\ GEC-Marconi Materials Technology Ltd, \\ Borehamwood, WDG IRX, UK
}

The gold-germanium-silicon alloy system has been demonstrated to be capable of furnishing solders melting below $450^{\circ} \mathrm{C}$ for gold jewellery with a fineness above 21 carats. The application of a thin gold plating to the alloys in foil form confers the requisite flow and spreading characteristics, when melted in a nitrogen atmosphere. Good colour matching can be achieved by a short post-soldering heat treatment, which modifies the alloy microstructure. The mechanical properties of these materials, as determined by shear and peel tests, are suitable for jewellery applications, although silicon and germanium differ considerably from gold with regard to their electrochemical potential, the continuous gold matrix ensures that the alloys maintain a high resistance to the acidic cleaning liquids used in domestic environments.

Most quality gold jewellery is made to 18 carat fineness. The joining of 18 carat items is traditionally carried out using 'gold solders', but strictly speaking these fillers are brazes rather than solders, having working temperatures in the range $750-900^{\circ} \mathrm{C}(1)$. There are disadvantages to using such high temperatures, particularly as to their effect on the mechanical strength and hardness of the jewellery items, and their use adds to the complexity and cost of the process (2). The possibility of identifying a true solder (melting below $450^{\circ} \mathrm{C}$ ) has been examined but no known alloy has previously been reported to simultaneously satisfy the other essential criterion of an 18 carat jewellery solder; namely colour matching to yellow gold.

An alternative approach which we have developed is diffusion soldering, where a layer of a low melting point base metal (e.g. tin, indium) is placed between gold components and melted. Keeping the layer of the base metal thin confers two major advantages, namely, the solder can be made to completely react with the gold components to achieve high caratage joints which are colour matched to yellow gold, and the mechanical properties of the gold-enriched joint are superior to those of the base metal and comparable with those of 18 carat gold (3). This diffusion soldering process has two practical constraints, however, namely the need for co-planar components and the pressure which must be applied during the joining operation.

The conventional 22 carat solder available in the
UK $(\mathrm{Au} / \mathrm{Ag} / \mathrm{Cu} / \mathrm{Zn})$ has a melting point range of 860 $880^{\circ} \mathrm{C}$, only $100^{\circ} \mathrm{C}$ below that for the alloy to be joined; this is clearly too narrow a difference for comfort. There is an increasing demand for 22 carat gold jewellery, and a suitable solder has therefore been sought (2). It is clear that the most practical high caratage gold solder would be a eutectiferous alloy, melting at a temperature well below that of gold itself. Two gold eutectic alloys that conform to this requirement are the $\mathrm{Au}-3 \mathrm{wt} \% \mathrm{Si}$ (melting point $=363^{\circ} \mathrm{C}$; Figure 1) and Au-12 wt $\%$ Ge (melting point $=361^{\circ} \mathrm{C}$;

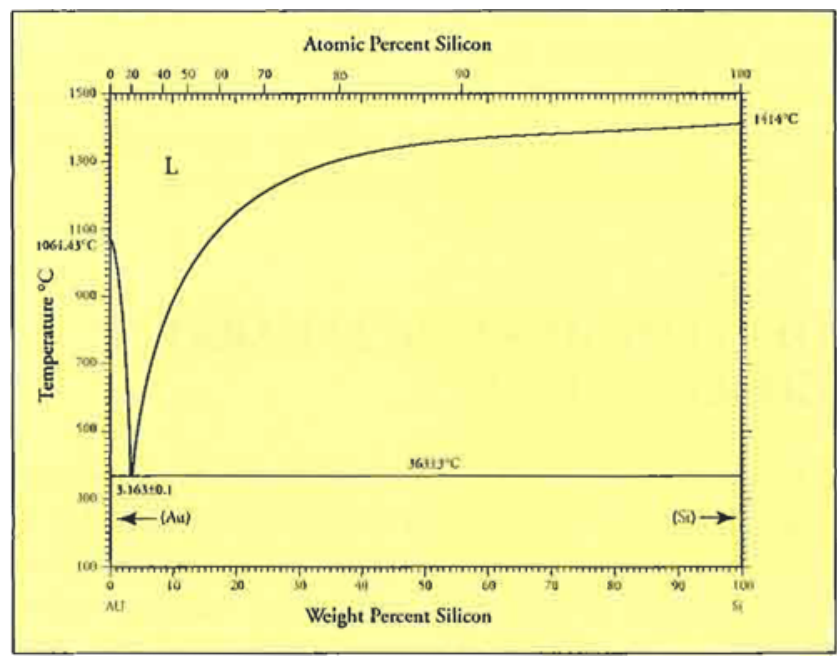

Figure 1 Gold-silicon phase diagram 


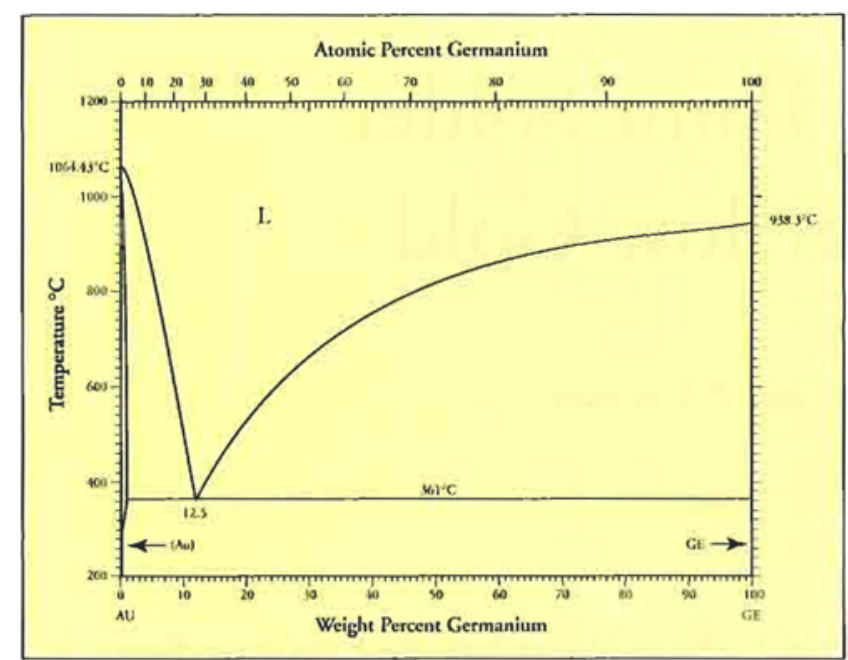

Figure 2 Gold-germanium phase diagram

Figure 2). Henceforth all compositions quoted are in weight percent.

Both these binary eutectic alloys are used in the electronics industry as high temperature solders, particularly for attaching integrated circuit chips to packages. They are also used in the fabrication of the electronic packages that are required to hermetically seal delicate components. Au-12Ge is used to seal-in feedthroughs to provide electrical connection between the circuitry within the packages and the external circuitry. However, die attachment using Au-3Si foil preforms requires that the components are 'scrubbed' (mechanically agitated) during the joining operation under a shroud of argon or nitrogen to achieve satisfactory wetting. The Au-12Ge solder does not require scrubbing but it does need to be used in an oxygen-free protective atmosphere containing some hydrogen ('forming gas') to minimise the formation of germanium oxide at the surface. These alloys are much stronger than conventional lead-tin solders, having ultimate strength (UTS) values that are approximately five times that of $\mathrm{Pb}-60 \mathrm{Sn}$ at $20^{\circ} \mathrm{C}$ but only one quarter the ductility (measured as percentage elongation) (4).

\section{DEVELOPMENT OF 22 CARAT GOLD SOLDER}

These two high gold binary alloys appeared to provide a suitable basis for a 22 carat solder but neither alloy is 22 carat. The Au-3Si is 23.3 carat while the Au-12Ge is 21.1 carat. However, a continuous eutectic valley extends from the Au-3Si composition to the Au12.5Ge in the ternary Au-Ge-Si system. This eutectic valley crosses the 22 carat gold fineness, as shown in Figure 3.

A series of alloys around the 22 carat composition was evaluated in order to assess the sensitivity of solderability to variation in composition. The experimental alloys were produced as foil by rapid solidification in order to avoid the need for laborious mechanical reduction. In the strip casting configuration of the rapid solidification process, a quantity of the molten alloy is forced through a slot onto a rapidly rotating wheel and the metal solidifies with a very high cooling rate (typically 1 million degrees per second) onto the wheel to form a continuous ribbon (5). The gold alloy foils produced by this method were in the range 100 $120 \mu \mathrm{m}$ thick and $3 \mathrm{~mm}$ wide.

As prepared, the foil was brittle, owing to the formation of the hard metastable $\mathrm{Au}_{3}(\mathrm{Si}, \mathrm{Ge})$ intermetallic compound, produced when the cooling rate exceeds $5^{\circ} \mathrm{C} / \mathrm{sec}$ (6). This embrittling phase is removed on heat-treating the foil, as described below.

Foils of two alloy compositions were prepared by strip casting, and made slightly gold-rich in order to optimise the colour match to yellow 22 carat gold and to provide a finite temperature range over which solid

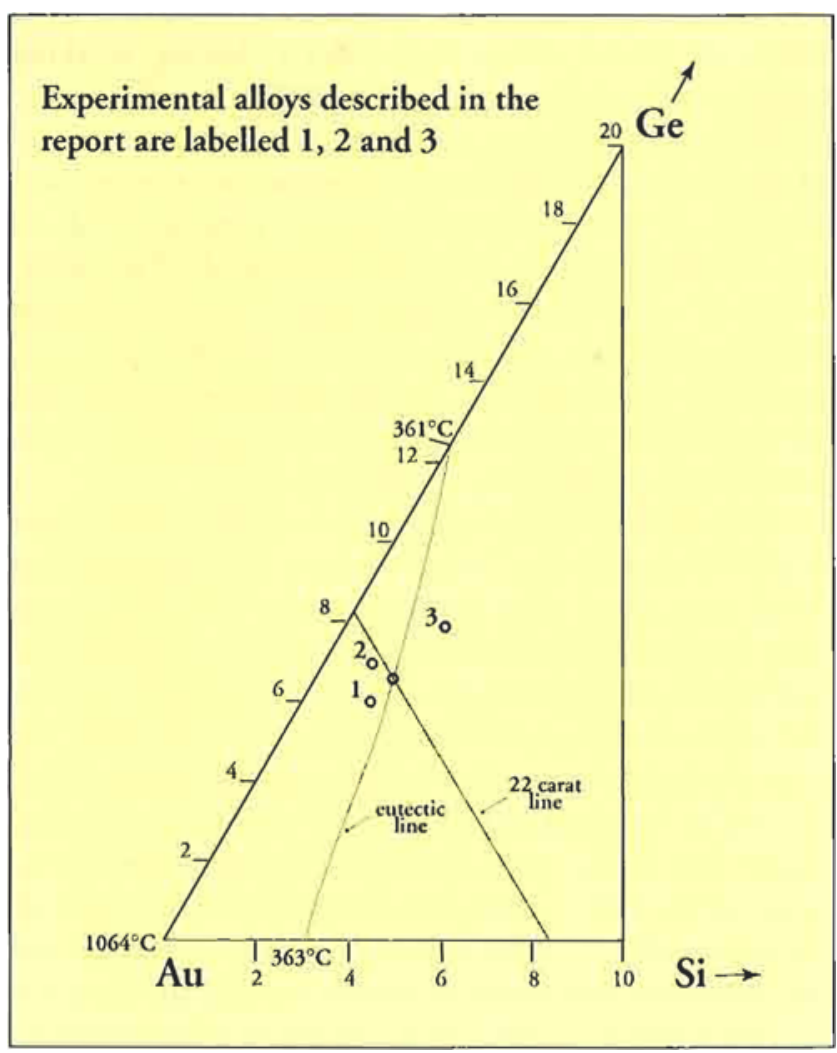

Figure 3 Partial gold-germanium-silicon phase diagram, in weight percent 
coexists with liquid phase in a paste, to enhance the gap filling characteristics. The compositions chosen and their corresponding melting ranges were $92.5 \mathrm{Au}-$ $6 \mathrm{Ge}-1.5 \mathrm{Si}$ (melting range: $362-374^{\circ} \mathrm{C}$, Alloy 1), and 92Au-7Ge-1 $\mathrm{Si}$ (melting range: $362-382^{\circ} \mathrm{C}$, Alloy 2 ).

These alloy compositions are shown in Figure 3. One is relatively rich in germanium and the other in silicon. There were two reasons for this, firstly, to round the compositions to integer or half-integer percentages and also to establish whether, in a best case situation, there was a chance of achieving good colour matching of the joint to yellow gold. Spread tests were carried out at $400^{\circ} \mathrm{C}$ (i.e. approximately $40^{\circ} \mathrm{C}$ superheat above the solidus temperature) on 18 carat substrates coated with a flash of pure gold. Both alloys gave satisfactory spread, but there was less dross produced with Alloy $I$ than with Alloy 2. This soldering experiment and all the other joining trials referred to below, were carried out in a nitrogen flow furnace without a flux.

The colour match between the solidified solder and the substrate remained unsatisfactory, the solder being relatively whitish but the spread was good, with a low contact angle between the solder and the substrate. This is demonstrated by a ' $T$ '-joint comprising a

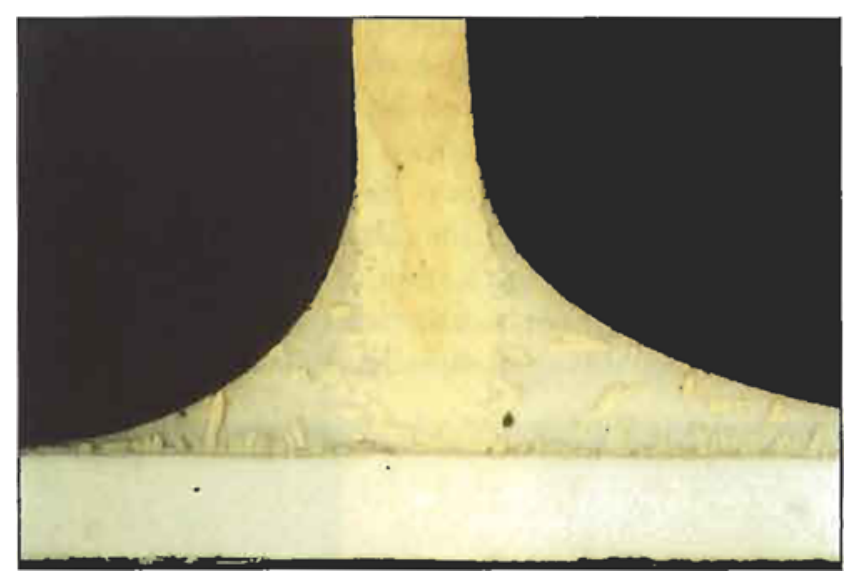

Figure 4 ' $T$ '-joint made with the 92.5Au-6Ge-1.5Si (wt\%) alloy to pure gold strip (upright) and gold flashed 18 carat coupon base, showing excellent filleting Processing conditions: $10 \mathrm{~min}$ at $425^{\circ} \mathrm{C}$ in flowing nitrogen atmosphere Magnification: x 50

foil of pure gold soldered tangentially to a gold flashed 18 carat gold coupon at $425^{\circ} \mathrm{C}$ in the nitrogen flow furnace (Figure 4). The photograph of the joint shows the excellent filleting, smooth profile and uniform microstructure of the solder.

Encouraged by these results, we replaced the 18 carat gold substrates by 22 carat gold, and omitted the overcoat of pure gold on the substrate metal used in the 18 carat case. The 22 carat composition used was 91.7Au-5.5Ag-2.8Cu, which is the one normally used for yellow gold. This alloy was prepared as an ingot and rolled to $150 \mu \mathrm{m}$ sheet, from which square coupons of about $0.5 \mathrm{sq} \mathrm{cm}$ were cut.

Another change effected at this time was to give the solder foil produced by rapid solidification a softening heat-treatment. The effect of the heat-treatment on the hardness of the $92.5 \mathrm{Au}-6 \mathrm{Ge}-1.5 \mathrm{Si}$ alloy is shown in Figure 5. Clearly, the metastable intermetallic decomposes fairly readily and if the foil is heated at $285^{\circ} \mathrm{C}\left(\sim 0.9 . \mathrm{T}_{\text {solidus }}\right)$, a heat-treatment time of $30 \mathrm{~min}$

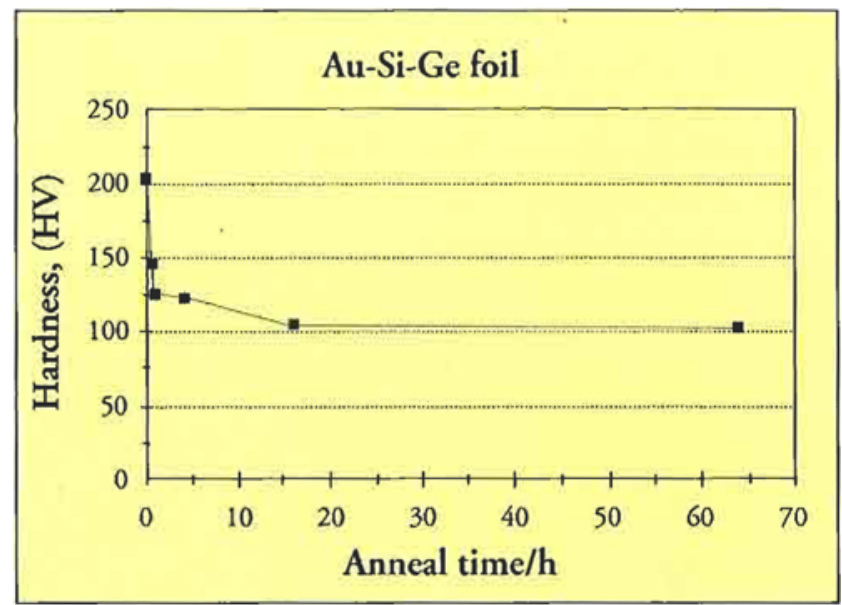

Figure 5 Effect of heat-treatment at $285^{\circ} \mathrm{C}$ in a nitrogen atrnosphere on the Vickers hardness of the $92.5 \mathrm{Au}$ 6Ge-1.5Si (wt\%) (Alloy 1), following strip casting by rapid solidification

is sufficient to restore ductility. The rapid softening observed is mirrored in the microstructure, which changes from one with a massive base metal phase to a finely divided distribution of $\mathrm{Si}-\mathrm{Ge}$ in the gold matrix. The heat-treatment also serves to yellow the foil which, as cast, has a whitish hue.

With a view to enhancing the spread characteristics of the solder, lengths of the foil of the $92.5 \mathrm{Au}-6 \mathrm{Ge}-1.5 \mathrm{Si}$ alloy were plated with approximately $1.5 \mu \mathrm{m}$ of pure gold. To assess the effect of this coating on solder spread, pieces of the foil $(-20 \mathrm{mg})$ were melted on 22 carat substrates at different temperatures, in the range from 400 to $500^{\circ} \mathrm{C}$ using foil prepared under four sets of conditions: (i) as cast, without gold plating; (ii) as cast, with gold plating; (iii) after softening heat-treatment, without gold plating; and (iv) after softening heat-treatment, with gold plating.

The two plated foils had greatly superior spread characteristics on 22 carat substrates. It was found that substantial spread was only achieved using the unplated foil 
when temperatures were $500^{\circ} \mathrm{C}$ or higher. On the other hand, joints made with softened foil, having a flash of pure gold $(-1.5 \mu \mathrm{m}$ thick) exhibited excellent filleting. 'The plating must be carried out after the heat-treatment: trials using foil which had first been plated and then heat-treated showed impaired solder spread, caused by the diffusion to the surface of silicon and its subsequent oxidation.

To achieve the best joint quality, the optimum soldering temperatures for the plated foil were in the range 425 $450^{\circ} \mathrm{C}$. At lower temperatures, there was evidence that the solder had not completely melted and flow was sluggish, whereas above $450^{\circ} \mathrm{C}$ dross formation became significant as did erosion of the substrates by the inolten solder.

The joints appeared whitish but a post-soldering heat-treatment of the soldered assemblies, carried out at $285^{\circ} \mathrm{C}$ for at least $120 \mathrm{~min}$ in a nitrogen shroud, yellowed them and produced an excellent colour match to the 22 carat gold components. This yellowing effect can be correlated with the joint microstructure, with the morpholo-

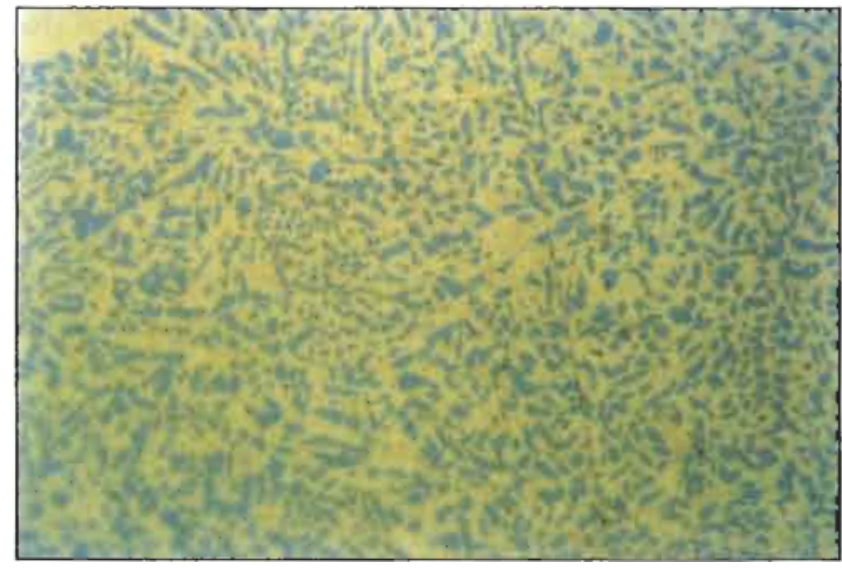

Figure 6 Microstructure of $92.5 A u-6 G e-1.5 S i$ (wt\%) (Alloy 1) before beat-treatment at $285^{\circ} \mathrm{C}$, showing dentritic form of the $\mathrm{Ge}$-Si precipitates

Magnification: x 500

gy of the Ge-Si precipitates changing from dendritic in shape to spheroidal, so that the same proportion of the precipitate phase accounts for a smaller proportion of the area of a free surface of the alloy. In consequence, the yellow gold matrix appears more dominant and the overall colour of the alloy changes accordingly (see Figures 6 and 7). This explanation is borne out by quantitative image analysis measurements which have shown that, whereas the Ge-Si phase represents $45 \pm 2 \%$ of the area of solder prior to the heat-treatment, it drops to $34 \pm 2 \%$ of the area afterwards. This difference is evidently sufficient to change the visible appearance of the alloy.

After coating with pure gold, the caratage of both foils is shifted in the gold-rich direction to a level

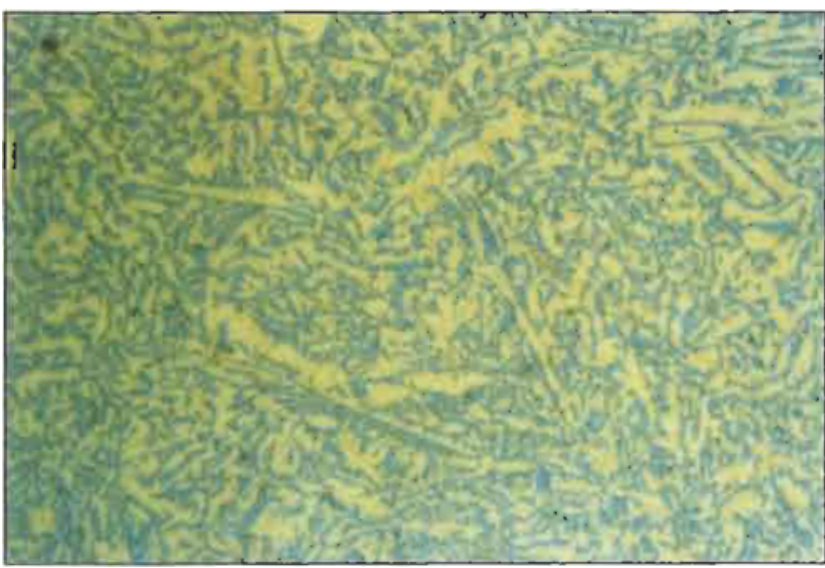

Figure 7 Microstructure of $92.5 \mathrm{Au}-6 \mathrm{Ge}-1.5 \mathrm{Si}$ (wt\%) (Alloy 1) after the heat-treatment at $285^{\circ} \mathrm{C}$ in nitrogen, showing spheroidal form of the Ge-Si precipitates Magnification: x 500

between 22.3 and 22.4. Accordingly, it was decided to examine the effect of a composition that was gold-deficient, to a similar extent, on the characteristics of the solder and to ascertain what effect, if any, the composition change has on the characteristics of the solder: The new composition was $90 \mathrm{Au}-7.9 \mathrm{Ge}-2.1 \mathrm{Si}$ (melting range: $362-376^{\circ} \mathrm{C}$, Alloy 3 - see Figure 3 ).

The alloy was cast as a foil $100 \mu \mathrm{m}$ thick by rapidsolidification. At this stage it was fairly brittle, having a hardness of over $200 \mathrm{HV}$, owing to the formation of the hard $\mathrm{Au}_{3}(\mathrm{Si}, \mathrm{Ge})$ phase which forms at high cooling rates (6). Heat treatment for 16 hours at $285^{\circ} \mathrm{C}$ reduced the hardness of the alloy by $50 \%$, as shown in Figure 5 . With the application of a $1.5 \mu \mathrm{m}$ thick coating of pure gold, the overall caratage was 21.7 and the melting range was approximately $362-370^{\circ} \mathrm{C}$.

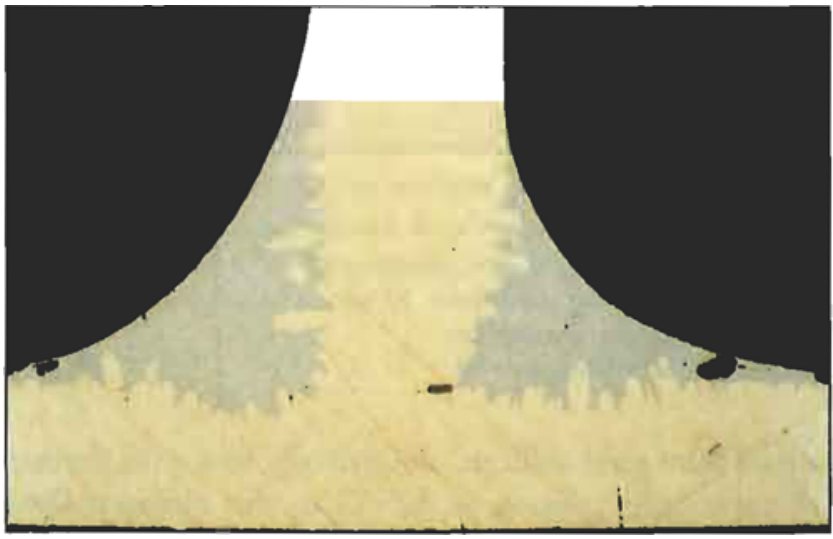

Figure 8 'T'-joint made with the 90Au-7.9Ge-2.1Si (wt\%) (Alloy' 3) to 22 carat gold coupons, showing excellent filleting Processing conditions: $10 \mathrm{~min}$ at $425^{\circ} \mathrm{C}$ in flowing nitrogen atmosphere Magnification: $\times 50$ 
Soldering trials were carried out at $425^{\circ} \mathrm{C}$ on this foil in a nitrogen flow furnace. The spread of the alloy on 22 carat gold substrates and joints made to ' $\mathrm{T}$ 'pieces of that caratage (Figure 8) indicated thar its performance was hardly distinguishable from that of the higher gold-content solder foils. The joint microstructures were also virtually identical and the post-soldering heat-treatment at $285^{\circ} \mathrm{C}$ in nitrogen had the same effect of yellowing the joint.

A foil that would produce a joint with a 22 carat composition would comprise a core strip of $91.6 \mathrm{Au}-$ $6.7 \mathrm{Ge}-1.7 \mathrm{Si}$, coated both sides with a $1.5 \mu \mathrm{m}$ layer of pure gold.

The effect of variation of the furnace atmosphere on the joining characteristics of the solder has been investigated. When an open shroud of nitrogen was employed at a flow rate of $0.5 \mathrm{~m} / \mathrm{sec}$ without a flux, the solder failed to wet and spread over the 22 carat substrates, and similar results were obtained at different flow rates. No difference was observed whether the workpiece was loaded gradually into the preheated furnace or whether it was brought up to the joining temperature inside the furnace. Commercially available fluxes were found to be unsatisfactory, accelerating the oxidation of the molten solder.

The implication from these trials is that an inert or reducing atmosphere furnace must be used. The furnace system used in our laboratory, which achieves a combined oxygen and water vapour level below $5 \mathrm{ppm}$, is a relatively simple one, however. Nitrogen gas drawn off a liquid nitrogen tank is passed directly through the furnace, sealed at one end, at a flow rate of $0.5 \mathrm{~m} / \mathrm{sec}$. At this flow rate, the outlet of the furnace can be left partly open provided that the soldering zone of the furnace is more than about $0.5 \mathrm{~m}$ from the outlet. Because there is good heat transfer via the flowing nitrogen to the workpiece, the latter needs to be kept in the hot zone of the furnace for no longer than $c a 3 \mathrm{~min}$.

\section{PHYSICAL PROPERTIES OF THE SOLDERED JOINTS}

Particular attention was paid to two sets of properties which are essential for jewellery alloys, namely mechanical integrity and corrosion resistance of the soldered joints.

\section{Mechanical strength of the joints}

Mechanical integrity was assessed via lap shear and peel resistance tests. The shear tests were carried out on lap jointed specimens, where the joint was formed in the waisted portion of the testpieces. The joint area was 2 $s q \mathrm{~mm}$. Failure of stressed testpieces always occurred in the 22 carat gold rather than in the joint, with the shear strengths in excess of $210 \mathrm{MPa}$. In all cases, failure in the peel specimens initiated in the $150 \mu \mathrm{m}$ thick 22 carat gold substrates and delamination was nor observed in well soldered specimens.

\section{Corrosion resistance of the joints}

There was initially some concern about the susceptibility of the solder to corrosion in an acidic environment, such as washing up liquid, arising from the large difference in electrochemical potential between silicon and germanium on the one hand and gold on the other (7). However, corrosion tests on soldered joints immersed for up to four days ( 100 hours) in water with a high concentration $(50 \%$ by volume) of washing-up liquid at $70^{\circ} \mathrm{C}$, demonstrated that the joints maintained their mechanical integrity and their shiny appearance; the silicon-germanium phase is a minority fraction by volume in the alloy (25\%) and is dispersed as fine isolated particles so that any corrosion is localised to the few exposed particles at the surface.

\section{FEASIBILITY OF A FURTHER REDUCTION IN THE SOLDERING TEMPERATURE}

The possibility that a further reduction in the soldering temperature could be achieved by adding one or more constituents was considered. Assessment of phase equibria indicated the existence of a ternary eutectic reaction between $\mathrm{Au}, \mathrm{Si}$ and $\mathrm{Sb}$ at $331^{\circ} \mathrm{C}$, representing approximately $30^{\circ} \mathrm{C}$ reduction from the $\mathrm{Au}-3 \mathrm{Si}$ and Au-12Ge binary eutectic alloys (8). The ternary eutectic composition, as determined in our laboratory is Au$9.25 \mathrm{Sb}-2.5 \mathrm{Si}$. This composition is of 21 carat fineness. A 22 carat composition lying close to the eutectic point and seleccted for examination was $91.6 \mathrm{Au}-6 \mathrm{Sb}$ $2.4 \mathrm{Si}$ (Alloy 4). Its melting range of $330^{\circ}-360^{\circ} \mathrm{C}$ is narrow, as befits a good solder, but this alloy was found to suffer from two drawbacks. Firstly, it is hard ( $230 \mathrm{HV})$ due to the presence of the $\mathrm{AuSb}_{2}$ phase as a large volume fraction and secondly, it is inadequately colour matched to 22 carat yellow gold, having a silvery white hue. Therefore, attempts were made to modify the composition to reduce its hardness and improve its colour match to yellow gold. Moreover, as it had been found that fluxes were not effective in promoting wetting and spreading of the alloy on gold sub- 
strates, and consequently minor additions of known spread promoters were added to destabilise the silica. A number of elements were investigated as spread promoters and softeners when added in minor quantities $(<1 \mathrm{wt} \%)$. The most useful results were obtained with zinc and germanium. Zinc was found to improve the solder spread and flow but only at concentrations above $0.5 \mathrm{wt} \%$ and zinc had the additional benefit of softening the alloy. At a zinc concentration of $0.75 \mathrm{wt} \%$ the hardness was reduced from $-320 \mathrm{HV}$ to $-128 \mathrm{HV}$. The further addition of up to $1 \mathrm{wt} \%$ of germanium was found to reduce the hardness further to $-124 \mathrm{HV}$. This is comparable with the hardness of the 22 carat Au-Ge$\mathrm{Si}$ solder in the annealed condition. The softening of the multicomponent alloy produced by the germanium could be associated with its observed grain refining of the primary silicon phase, with the average silicon grain size being reduced from $-50 \mu \mathrm{m}$ to $-10 \mu \mathrm{m}$. The germanium addition also reduced the melting point of the alloy, as might be expected considering that germanium is isomorphous with silicon but has a lower melting point. Thus, a $92 \mathrm{Au}-3 \mathrm{Ge}-3 \mathrm{Sb}-1.5 \mathrm{Si}-0.5 \mathrm{Zn}(\mathrm{wt} \%)$ (Alloy 5) was found to possess a melting range of $310-325^{\circ} \mathrm{C}$. Rare earth additions also had some beneficial effects, as shown in Figure 9.

These additions conferred noticeable benefits, but they failed to achieve the requisite characteristics for a 22 carat gold solder. At these levels of additions, the alloy was noticeably whitened but it had the propensity to react with and erode the 22 carat gold substrate at the expense of filling the joint (Figure 10). Both features are inextricably linked with the antimony content and the formation of $\mathrm{AuSb}_{2}$ although the whitening effect is exacerbated by the zinc addition.

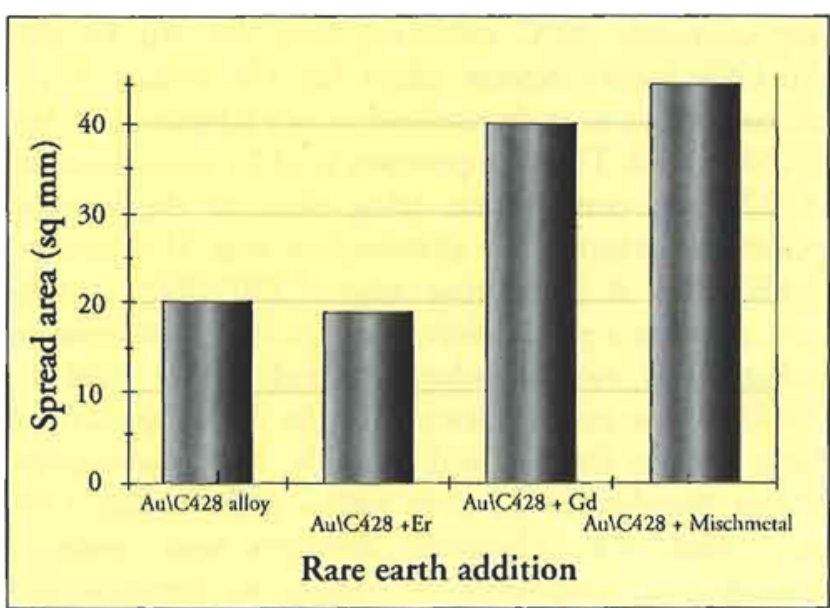

Figure 9 Effect of adding $-0.5 w t \%$ of rare earths to the spread characteristics of the $92 \mathrm{Au}-3 \mathrm{Ge}-3 \mathrm{Sb}-1.5 \mathrm{Si}-0.5 \mathrm{Zn}$ $(w t \%)$ (Alloy $5=A u \backslash C 428)$
Figure $1092 A u-3 G e-3 S b-1.5 S i-0.5 Z n(w t \%)$ experimental alloy (Alloy 5) melted onto a pure gold flashed 18 carat gold substrate at $460^{\circ} \mathrm{C}$ in nitrogen (unfluxed), showing deep reaction with the substrate but little lateral spread

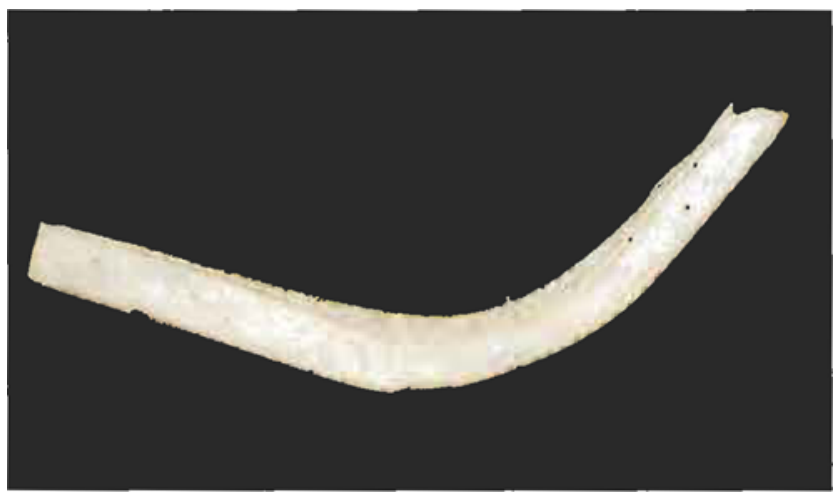

(a) Magnification: $x 5 \dagger$

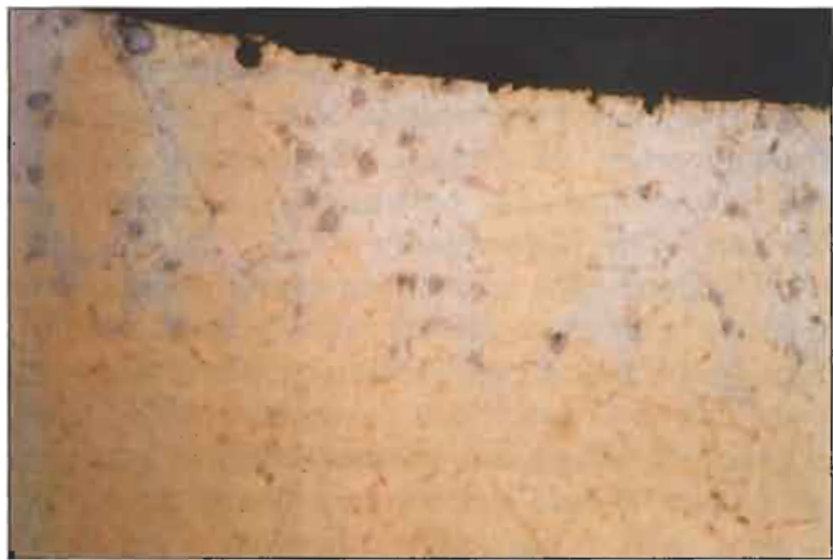

(b) Magnification: $\times 125 \dagger$

\section{CONCLUSIONS}

A 22 carat solder has been developed suitable for use with gold jewellery items of similar fineness. Joints of excellent quality (well filled and with rounded fillets) can be produced using this solder in a fluxless joining operation and an inert gas atmosphere having low background levels of oxygen and water vapour. It has not been found possible to join in air under the cover of flux with the new solder, but a suitable inert gas atmosphere furnace is simple to construct and operate and the method has advantages over fluxed soldering in air. Improvements include the removal of a requirement to apply flux and to clean the joined assemblies afterwards, and improved

\footnotetext{
† Please note magnification may not be accurate due to reproduction process in publishing.
} 
reproducibility of the soldering operation. Otherwise the process is highly tolerant with respect to compositional variation of the solder (from 21.7 to 22.4 carats), soldering time (3 to 25 minutes) and temperature (425$450^{\circ} \mathrm{C}$ ). The melting point could be further reduced by alloying with antimony, but this element whitens the alloy and impairs its gap-filling characteristics.

While the joints are initially whitish, a simple heattreatment achieves good colour matching to yellow gold. This heat-treatment could be integrated into the soldering cycle. The joints to 22 carat gold items made with the new solder are mechanically strong, having a strength in excess of $200 \mathrm{MPa}$ and more than adequate corrosion resistance for jewellery use; consequently the new method has the potential for raising the level of technology used in jewellery production.

\section{ACKNOWLEDGEMENTS}

This work was supported by the World Gold Council. The contributions of Dr Giles Humpston, of GMMT Caswell, to the study of the multicomponent gold alloys and $\mathrm{Mr}$ James Vincent, for strip casting the alloys to foil, Chris Fisher for gold plating, and Dr Martin Harrison for carrying out mechanical tests (all of the Hirst Division, GMMT Borehamwood), are also gratefully acknowledged.

\section{ABOUT THE AUTHORS}

Dr Jacobson manages The Materials Processing Group at the Hirst Division of GMMT Ltd, and possesses wide experience in metal joining and bonding methods, having graduated as a physicist and obtained his doctorate in Materials Science. He has worked in the joining of gold for ten years and made many original contributions to the field.

Dr Sangha is an electrical engineer whose doctorate is in Materials Science. He has applied his knowledge to the assessment of gallium arsenide semiconductor systems and the development of low melting point brazes for joining a wide range of aluminium engineering alloys before investigating the gold systems described herein.

\section{REFERENCES}

1 W.S. Rapson and T. Groenewald, 'Gold Usage', Academic Press, 1978, p. 80

2 G. Humpston and D.M. Jacobson, Gold Bull., $1994,27,110$

3 G. Humpston, D.M. Jacobson and S.P.S. Sangha, Gold Bull., 1993, 26, 90

4 ASM Handbook, Volume 6: 'Welding, Brazing and Soldering', 1993 , p. 968

5 H. Jones, 'Rapid Solidification of Metals and Alloys', Monograph No. 8, The Institution of Metallurgists, London, 1982

6 A.A. Johnson and D.N. Johnson, Mater. Sci. Eng., 1983, 61, 231

7 J.F. Shackelford, W. Alexander and J.S. Park, (eds.), CRC Handbook 1994, p. 667

8 G. Humpston and S.P.S. Sangha, J. Phase Equilibria, 1993, 14, 1 